\title{
OPTIMIZATION OF CAPACITIES OF WIND AND SOLAR POWER PLANTS IN THE INTERSTATE POWER GRID IN NORTH-EAST ASIA TAKING INTO ACCOUNT THE INTERMITTENCE OF THEIR POWER OUTPUT
}

\author{
Leonid N. Trofimov ${ }^{1}$, Ivan L. Trofimov ${ }^{1, *}$ \\ ${ }^{1}$ Melentiev Energy Systems Institute of Siberian Branch of the Russian Academy of Sciences, Electric Power Systems Department, \\ 664033, 130, Lermontova Str., Irkutsk, Russia
}

\begin{abstract}
The paper considers the problems of optimization of wind and solar power plants (WPP and SPP) expansion and it operating modes in the prospective interstate power grid (ISPG) in Northeast Asia, taking into account the intermittence of their power output. A series of experiments with variations in the profiles of WPP and SPP in the model nodes were carried out. Also authors carried out some additional experiments with the increase in fuel costs for fossil fuel power plants due to environmental restrictions. As a result, an assessment of the character of the changes in the solution of the model for new installed capacities and their costs, depending on the variations for the profiles of the contributions generation of WPP and SPP to cover daily electrical load graphs, is obtained.
\end{abstract}

\section{Introduction}

The increase in the share of power plants on renewable energy sources (RES) is a global trend. However, the operation of these types of power plants (Wind - WPP and Solar - SPP) has its own characteristics that require study and analysis when integrating them into power grid.

A feature of RES is the intermittence of their power output (contribution to the power system), which is difficult to predict. Taking into account the contribution of WPP and SPP to electricity generation, it is impossible to plan the amount of this contribution to cover the average daily electric load. Therefore, when optimizing new capacities in power system expansion scenarios, taking into account the required $20 \%$ of capacity reservation at peak load points, WPP and SPP contributions must be completely eliminated. In other words, the power system must be able to pass all peak load points without considering the generating capacity WPP and SPP. Taking into account the economic parameters of these power plants, the quantitative ratio of capacities for renewable and non-renewable energy resources in scenarios of interstate power grid expansion is an important parameter calculated when solving the optimization problem.

\section{Computational experiments on the ORIRES model taking into account the}

increase in fuel costs for fossil fuel power plants due to environmental restrictions

A number of computational experiments were carried out on the ORIRES model by using the Geo-information computing system [1-6]. In this model the optimization of generation capacities expansion and it operating modes are determined by the minimum cost of their construction, operation and fuel consumption, if all technical constrains are satisfied. Along with optimization of new capacities of thermal, nuclear and hydraulic power plants, the involvement of each type of power plants in covering graphs of daily and annual electric load is optimized too. The obtained installed capacities and generation profiles of these types of power plants are optimal in terms of minimizing total costs.

It was some scenarios with the possible increase in fuel costs due to an increase in the $\mathrm{CO}_{2}$ emission tax. In relation to the basic scenario, $\mathrm{CO}_{2}$ tax of 30,40 and 60 USD per 1 ton of emission was taken into account [7-9]. In each of these three scenarios, fuel costs were recalculated in USD / $\mathrm{kWh}$, respectively.

For each of these scenarios, non-interconnected power systems and interconnection of power systems into Interstate Power Grid in Northeast Asia (NEA ISPG) were considered. Eight possible scenarios for ISPG expansion in Northeast Asia were analysed. Calculation of two basic scenarios, for non-

\footnotetext{
* Corresponding author: $\mathrm{t}$ john88@,isem.irk.ru
} 
interconnected nodes (power systems) and ISPG showed the integration effect (benefits) of interconnection in the form of reducing the total costs and saving the additions of new generating capacities. Table 1 shows the results of calculating two basic scenarios, non-interconnected power systems and interconnection. The bottom raw of the table shows the integration effects.

Table 1. Benefits of the interconnection of power systems.

\begin{tabular}{|c|c|c|c|c|c|}
\hline \multirow[t]{2}{*}{ Name } & \multicolumn{3}{|c|}{ Capital investments, \$ Bln. } & \multicolumn{2}{|c|}{ Capacity, GW } \\
\hline & $\begin{array}{l}\text { power } \\
\text { plants }\end{array}$ & $\begin{array}{l}\text { electric } \\
\text { ties }\end{array}$ & Total & $\begin{array}{l}\text { installed } \\
\text { capacity }\end{array}$ & addition \\
\hline $\begin{array}{l}\text { Base } \\
\text { case } \\
\text { scenario } \\
2040 \\
\text { Non- } \\
\text { connect } \\
\text { ion }\end{array}$ & 854.8 & 0.214 & 855.05 & 2582.3 & 651.68 \\
\hline $\begin{array}{l}\text { Base } \\
\text { case } \\
\text { scenario } \\
2040 \\
\text { intercon } \\
\text { nection }\end{array}$ & 745.3 & 39.27 & 784.63 & 2523.7 & 593.15 \\
\hline $\begin{array}{l}\text { Resulti } \\
\text { ng } \\
\text { effect }\end{array}$ & 109.5 & -39.05 & 70.42 & 58.5 & 58.53 \\
\hline
\end{tabular}

The interconnection of power systems in NEA ISPG, as shown by the experiments, can save up to $70 \$$ Bln. capital investments and $58 \mathrm{GW}$ of new generating capacities. Scenarios with a consistent and substantial increase in the cost of the fuel component showed that the integration effect of interconnection remains for all scenarios.

When the cost of the fuel of thermal power plants increases, the generation of these types of power plants is replaced by the generation of wind and solar facilities. The next two diagrams illustrate the percentage of annual generation of various types of power plants in the basic scenarios (without fuel cost increases) - Figure 1, and with an increase of fuel costs due to introduction of emission tax in the amount of USD 60 per ton of $\mathrm{CO}_{2}-$ Figure 2.

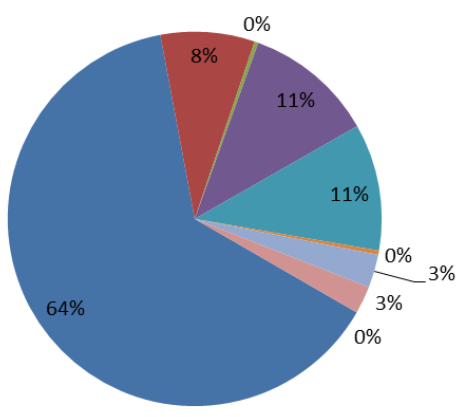

Fig. 1. Base case scenario (without $\mathrm{CO}_{2}$ emission tax), noninterconnected power systems.

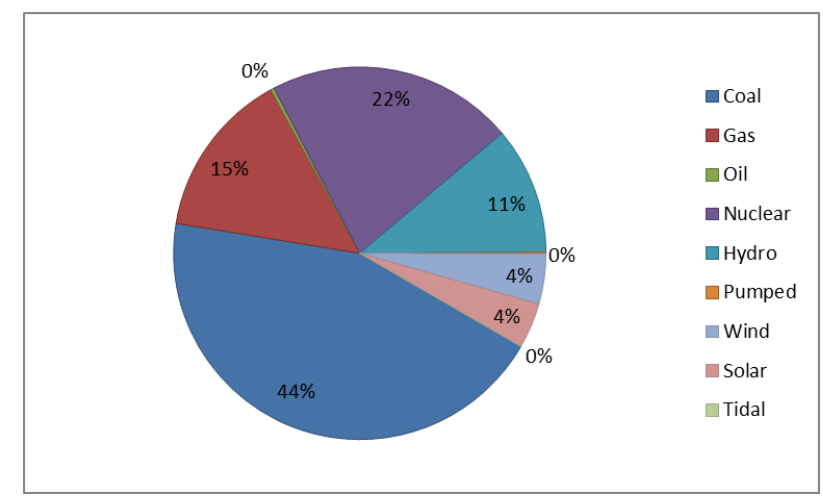

Fig. 2. Base case scenario, tax on $\mathrm{CO}_{2}$ is equal to $60 \$ \mathbf{t}$ ton, non-interconnected power systems.

The calculation of each scenario optimizes the additions of new capacities by type of power plants. Table 2 shows the additions of new capacity for four scenarios of noninterconnected power systems: the base case scenario and scenarios with the $\mathrm{CO}_{2}$ taxes $(30$ \$/ton, 40 \$/ton and $60 \$ /$ ton).

Table 2. New capacities by fuel type, GW, non-interconnected power systems, scenarios with $\mathrm{CO}_{2}$ taxes.

\begin{tabular}{|l|l|l|l|l|}
\hline & $\begin{array}{l}\text { Base case } \\
\text { scenario } \\
\text { (no taxes) }\end{array}$ & $\begin{array}{l}\mathbf{3 0} \\
\text { \$/ton }\end{array}$ & $\begin{array}{l}\mathbf{4 0} \\
\text { \$/ton }\end{array}$ & $\begin{array}{l}\mathbf{6 0} \\
\text { \$/ton }\end{array}$ \\
\hline Coal & 385.21 & 312.15 & 286.94 & 243.74 \\
\hline Gas & 29.65 & 45.53 & 56.45 & 24.52 \\
\hline Hydro & 75.42 & 56.16 & 76.02 & 84.18 \\
\hline $\begin{array}{l}\text { Pumped } \\
\text { storage }\end{array}$ & 90.29 & 87.40 & 2.20 & 7.04 \\
\hline Nuclear & 70.69 & 132.80 & 217.53 & 217.89 \\
\hline Wind & 0.23 & 0.23 & 0.23 & 91.20 \\
\hline Solar & 0.19 & 0 & 0 & 122.66 \\
\hline Total & $\mathbf{6 5 1 . 6 8}$ & $\mathbf{6 3 4 . 2 7}$ & $\mathbf{6 3 9 . 3 7}$ & $\mathbf{8 4 5 . 8 6}$ \\
\hline
\end{tabular}

Table 3. New capacities by fuel type, GW, interconnection of power systems, scenarios with $\mathrm{CO}_{2}$ taxes.

\begin{tabular}{|l|l|l|l|l|}
\hline & $\begin{array}{l}\text { Base case } \\
\text { scenario } \\
\text { (no taxes) }\end{array}$ & $\mathbf{3 0}$ \$/ton & $\mathbf{4 0 ~ \$ / t o n ~}$ & $\begin{array}{l}\mathbf{6 0} \\
\text { \$/ton }\end{array}$ \\
\hline Coal & 380.71 & 302.23 & 255.09 & 243.74 \\
\hline Gas & 4.02 & 22.49 & 19.78 & 24.52 \\
\hline Hydro & 79.98 & 58.88 & 84.18 & 84.18 \\
\hline $\begin{array}{l}\text { Pumped } \\
\text { storage }\end{array}$ & 90.29 & 85.20 & 0 & 7.04 \\
\hline Nuclear & 38.15 & 104.33 & 217.89 & 217.89 \\
\hline Wind & 0 & 0 & 0 & 91.20 \\
\hline Solar & 0 & 0 & 0.97 & 122.66 \\
\hline Total & $\mathbf{5 9 3 . 1 5}$ & $\mathbf{5 7 3 . 1 3}$ & $\mathbf{5 7 7 . 9 1}$ & $\mathbf{7 9 1 . 2 3}$ \\
\hline
\end{tabular}

When the cost of the fuel increases, new coal capacity additions are reduced. First, this is due to increase in the new capacities of nuclear power plants, and in the last scenario, when the increase in capacities 
of nuclear power plants is not possible - this is due to increase in the new capacities of WPP and SPP. As a result, the addition of new capacities of wind and solar took place only in the scenario with increasing fuel costs, corresponding to the $\mathrm{CO}_{2}$ emission tax to 60 \$/ton.

Table 3 shows four other scenarios with the power interconnection in NEA. Due to the integration effect, the addition of new capacities decreased, but the trends in their capacity structure remained the same. There is still a tendency to reducing the addition of new coalfired capacities in NEA ISPG, primarily due to the increase of new capacities of nuclear power plants, and then - WPP and SPP. In all scenarios, the savings in addition of new capacities due to interconnection are 7$10 \%$, which confirms the integration effect for all scenarios.

\section{Computational experiments taking into account the intermittence of the power output of wind and solar power plants}

The specifics of optimizing the new capacities of wind and solar are the intermittence of their electric power output. The ORIRES model for all other types of power plants optimizes not only the addition of new capacities, but also their power generation, taking into account the daily electric load graph for each node (power system).

In the base case scenario, the profiles of daily power generation graphs of WPP and SPP in the model are fixed. The profile of the graphs of WPP and SPP in the solving process of the optimization problem does not change, but installed capacities can be optimized in a given range by minimizing the costs of the ISPG as a whole.

For WPP and SPP, utilization hours and power output configuration are not optimized. Due to this, the hourly distribution of power output of WPP and SPP for each calculation is set by a fixed graph.

It was necessary to find out how changes in utilization (operation) hours and configuration of daily power generation of WPP and SPP affect the solution of the optimization problem.

For this purpose, a number of computational experiments were carried out, in which the volume of the contribution of WPP and SPP to the total generation was varied, and the shape of their daily power generation graph was changed.

In these experiments, the graphs of electric load of WPP was changed for all electric power systems (EPS) of China for each of the four seasons of the year. Particularly, capacity factor of WPP is increased up to $40 \%$. Previously, for different nodes, depending on the year seasons, the capacity factor of WPP was ranged from $12 \%$ to $35 \%$.

As an example, the authors used the graph of electric load of WPP in Northeast and Center (NEC) of China, in the autumn season, in which the capacity factor of WPP was $18 \%$, which corresponds to 4.3 utilization hours per day. For the experiment, this capacity factor of WPP was increased up to $40 \%$, which corresponds to 9.6 utilization hours. Figures 3 and 4 show correspondingly the above noted graphs of electric load of WPP for the NEC of China (autumn), normalized to 1 .

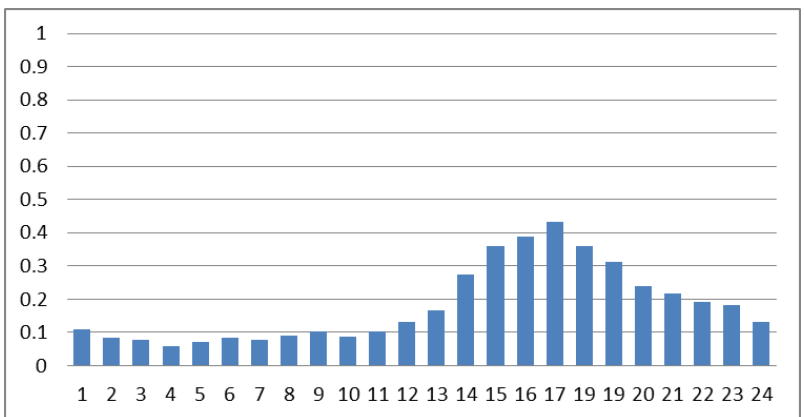

Fig. 3. Utilization hours of WPP are 4.3 (18\% capacity factor), wind speed is $3-4 \mathrm{~m} / \mathrm{sec}$.

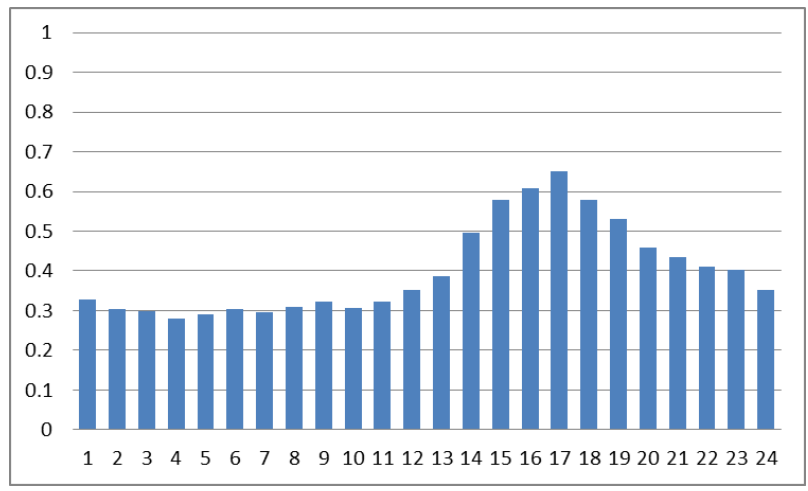

Fig. 4. Utilization hours of WPP are 9.6 (40\% capacity factor), wind speed is $8-9 \mathrm{~m} / \mathrm{sec}$.

The second graph of the daily power generation of WPP differs from the first in that the area under it (reflecting generation for each of the 24 hours) corresponds to utilization (operating) hours is 9.6 per day, wind speed $8-9 \mathrm{~m} / \mathrm{sec}$. This is interpreted as an increase in the average total wind generation during the day.

It is quite obvious that all of this entailed changes in solving the optimization problem. Figure 5 shows the increase in the share of WPP electricity generation for the 2040 target year from $4 \%$ to $7 \%$ compared to the diagram in Figure 2. As a result, generation on nonrenewable energy resources decreased.

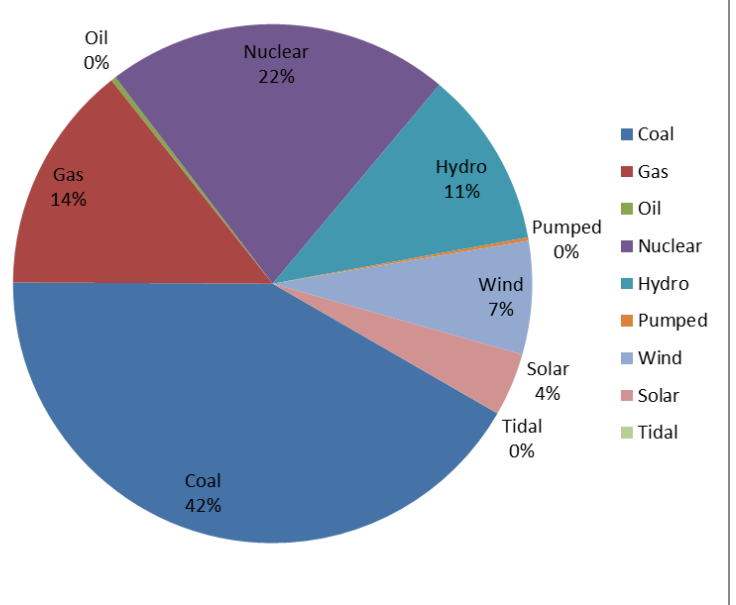


Fig. 5. Non-interconnected power systems, tax on $\mathrm{CO}_{2}$ is equal to $60 \$ /$ ton. Wind speed is $8-9 \mathrm{~m} / \mathrm{sec}$.

Comparison of the diagrams in figures 2 and 5 shows significant changes in the structure of electricity generation for the target year. Generation can be calculated similarly if we assume that the power output of WPP is reduced. However, a change in the generation structure only leads to higher or lower costs for the fuel component of the annual balance, but does not change the structure and additions of new generating capacity. Table 4 shows a comparison of the main indicators of two scenarios in which the $\mathrm{CO}_{2}$ emission tax is 60 \$/ton, and they differ from each other by the increased utilization (operating) hours for WPP in China power systems (the second one).

Table 4. Scenarios comparison: normal and increased utilization hours of WPP.

\begin{tabular}{|l|l|l|l|l|l|l|}
\hline Name & \multicolumn{2}{|l|}{$\begin{array}{l}\text { Values of the objective } \\
\text { function, } \$ \text { Bln./year }\end{array}$} & \multicolumn{2}{|c|}{ Capacity, GW } \\
\cline { 2 - 7 } & $\begin{array}{l}\text { power } \\
\text { plant }\end{array}$ & $\begin{array}{l}\text { fuel } \\
\text { cost }\end{array}$ & $\begin{array}{l}\text { elect } \\
\text { ric } \\
\text { ties }\end{array}$ & Total & $\begin{array}{l}\text { Installe } \\
\mathrm{d}\end{array}$ & $\begin{array}{l}\text { addition } \\
\mathrm{s}\end{array}$ \\
\hline $\begin{array}{l}\text { 60\$/t } \\
\text { wind } \\
3-4 \\
\mathrm{~m} / \mathrm{sec}\end{array}$ & 307.7 & 516.9 & 0.01 & 824 & 2776 & 845.8 \\
\hline $\begin{array}{l}60 \$ / \mathrm{t} \\
\text { wind } \\
8-9 \\
\mathrm{~m} / \mathrm{sec}\end{array}$ & 307.9 & 506.6 & 0.01 & 814 & 2776 & 845.8 \\
\hline $\begin{array}{l}\text { Result } \\
\text { ing } \\
\text { effect }\end{array}$ & $\mathbf{- 0 . 2}$ & $\mathbf{1 0 . 3}$ & $\mathbf{0}$ & $\mathbf{1 0}$ & $\mathbf{0}$ & $\mathbf{0}$ \\
\hline
\end{tabular}

The cost of the fuel component of the objective function has decreased due to the greater share of generation at WPP. At the same time, the structure of addition of new capacities has not changed. As a result, with increasing utilization hours of WPP, the addition of new capacities will still not change.

To check the influence of the profile (configuration) of the graphs of electric load of WPP, the authors were carried out the additional calculations with a change in the hourly profile (configuration) of the graphs of the electric load of WPP, with the same numbers of utilization hours.

In the NEC of China, the peak of the maximum of the graph of electric load of WPP was assumed to move from evening hours to morning hours (see the article of L.N. Trofimov et al. "The assessment of integration effects accounting the stochasticity of wind and solar power plants generation in the Asian Power Grid" [10]).

At the same time, the number of utilization hours of WPP for all EPS of China was also increased to 9.6 hours (which is equal to $40 \%$ capacity factor). In addition to this, the authors carried out some calculations where the graphs of electric load of WPP were given in a stochastic manner, with the same number of utilization hours.

As a result, a series of experiments on changing the profiles (configuration) of graphs of the electric load of
WPP, with the same utilization hours, showed that these changes practically do not affect the solution of the optimization problem.

The annual fuel costs of the objective function were changed within $0.1 \%-0.2 \%$. A much more important parameter is the average number of utilization hours (or capacity factor) of WPP for the total generation of the node.

\section{Conclusions}

The experiments carried out showed:

1. Changes in the average annual utilization hours of wind and solar power plants affect only the structure of electricity generation. This leads, respectively, to a decrease or increase in the consumption of fossil fuel in the target year. At the same time, the structure of the addition of new capacities remains unchanged.

2. The increase in the tax on $\mathrm{CO}_{2}$ emissions will cause, first of all, the replacement of new capacities of coal-fired power plants with the new capacities of nuclear power plants. Only when the limit on their additions is exhausted, the addition of the new capacities of wind and solar power plants become profitable.

3. With the maximum increase in $\mathrm{CO}_{2}$ tax, the share of installed wind and solar capacities will increase to $20 \%$, compared to $10 \%$ in the basic scenarios (without the $\mathrm{CO}_{2}$ emission taxes).

The research was carried out under State Assignment Program No. III. 17.6.2 (AAAA-A17117030310447-3) of the Fundamental Research of Siberian Branch of the Russian Academy of Sciences and partly supported by the Russian Foundation of Basic Research, Grant No. 18-07-00495-A.

\section{References}

1. L.S. Belyaev, S.V. Podkovalnikov, V.A. Savelyev, L.Yu. Chudinova, The effectiveness of interstate electric ties (Novosibirsk: Nauka, 2008) [in Russian]

2. L. Belyaev, L. Chudinova, O. Khamisov, G. Kovalev, L. Lebedeva, S. Podkovalnikov and V. Savelev, Studies of interstate electric ties in Northeast Asia, International Journal of Global Energy Issues, 17,3 (2002)

3. S.V. Podkovalnikov, I.L. Trofimov, L.N. Trofimov, L.Yu. Chudinova, The Specialized System for Processing of Interstate Power Grids Data, Energy Systems Research Journal, 1 (2018)

4. S.V. Podkovalnikov, I.L. Trofimov, L.N. Trofimov, L.Yu. Chudinova, L.S. Belyaev, V.A. Savelev Computing and Information System for Research of Prospective Electric Power Grids Expansion // Yugoslav Journal of Operations Research, [S.l.], 29, 4 (2019)

5. S.V. Podkovalnikov, I.L. Trofimov, L.N. Trofimov and L.Yu. Chudinova, "The Computing and Information System for Study of Scenarios for Interstate 
Power Grids Expansion," 2019 16th International Conference on Electrical Engineering/Electronics, Computer, Telecommunications and Information Technology (ECTI-CON), Pattaya, Chonburi, Thailand (2019)

6. S.V. Podkovalnikov, V.A. Savelev, O.V. Khamisov, L.Yu. Chudinova, "Justification of Effectiveness of International Power Interconnections with Separation of Effects between Participants, Automation and remote control", 10 (2018).

7. Paris Agreement under the United Nations Framework Convention on Climate Change. December 12 (2015)

8. Decree of the Government of the Russian Federation. No. 1228. September 21 (2019)

9. P. Luckow, E. Stanton, S. Fields et al. Spring 2016 National Carbon Dioxide Price Forecast. Cambridge. Massachusetts. 2016. http://www.synapseenergy.com/sites/default/files/2016-Synapse-CO2Price-Forecast-66-008.pdf

10. L.N. Trofimov, I.L. Trofimov, The assessment of integration effects accounting the stochasticity of wind and solar power plants generation in the Asian Power Grid // Rudenko International Conference "Methodological problems in reliability study of large energy systems" (RSES 2019). E3S Web Conf., 139 (2019) 